\title{
Chronic converting enzyme inhibition normalizes QT interval in aging rats
}

V.J. Dias da Silva, E. Ferreira $\mathrm{Neto}^{1}$,

H.C. Salgado ${ }^{2}$ and

R. Fazan Júnior ${ }^{1}$

\author{
1Departamento de Ciências Biológicas, Faculdade de Medicina do Triângulo Mineiro, \\ U beraba, M G, Brasil \\ 2Departamento de Fisiologia, Faculdade de Medicina de Ribeirão Preto, \\ Universidade de São Paulo, Ribeirão Preto, SP, Brasil
}

\section{Correspondence \\ V.J. Dias da Silva \\ Departamento de Ciências Biológicas \\ Faculdade de Medicina do \\ Triângulo Mineiro \\ Praça Manoel Terra, 330 \\ 38015-050 Uberaba, MG \\ Brasil \\ Fax: + 55-34-3318-5466 \\ E-mail: valdo@ mednet.com.br}

Presented at the IV International Symposium on Vasoactive Peptides, Belo Horizonte, MG, Brazil,

October 19-21, 2001.

Research supported by PRONEXCNPq, FAPESP and FUNEPU.

E. Ferreira Neto was supported by a scientific training grant from PIBIC program of CNPq.

Received N ovember 22, 2001 Accepted May 3, 2002

\section{Abstract}

The aim of the present study was to investigate the effects of converting enzyme inhibition by captopril on ECG parameters in aged rats. Four-month-old male rats received captopril dissolved in tap water $(0.5 \mathrm{mg} / \mathrm{l})$ or tap water for 2 or 20 months. At the end of treatment, under anesthesia, RR and PR interval, P wave and QRS duration, QT and corrected QT interval were measured in all animals. On the following day, chronic ECG (lead II) recordings were performed to quantify supraventricular (SVPB) or ventricular premature beats (VPB). After sacrifice, the hearts were removed and weighed. RR interval was similar in young and untreated aged rats, but significantly larger in aged rats treated with captopril. P wave and QRS length did not differ among groups. PR interval was significantly larger in old than in young rats and was not affected by captopril. Corrected QT interval was larger in aged than in young rats $(117 \pm 4 v s 64 \pm 6 \mathrm{~ms}, \mathrm{P}<0.05)$ and was reduced by captopril $(71 \pm 6 \mathrm{~ms}, \mathrm{P}<0.05)$. VPB were absent in young rats and highly frequent in untreated old animals $(8.4 \pm 3.0 / 30$ min). Captopril significantly reduced VPB in old rats $(0.3 \pm 0.1 / 30$ $\min , \mathrm{P}<0.05)$. The cardiac hypertrophy found in untreated aged rats was prevented by captopril ( $3.44 \pm 0.14$ vs $3.07 \pm 0.10 \mathrm{mg} / \mathrm{g}, \mathrm{P}<0.05)$. The beneficial effects of angiotensin converting enzyme inhibition on the rat heart during the aging process are remarkable.

\section{Introduction}

Several electrocardiographic (ECG) indices have been proposed to identify patients at risk of sudden death, including the QT interval length and/or dispersion (1-3). Clinical trials have demonstrated that QT interval is particularly altered in situations such as cardiac hypertrophy (4) or myocardial ischemia (5), but is normalized by appropriate therapy (6). The myocardial alterations that occur with aging $(7,8)$ alter ECG parameters such as QT interval $(9,10)$.

Aging is associated with electrical and morphological changes of the myocardium $(7,8)$, increasing significantly the incidence of life-threatening cardiac arrhythmias and sudden death in aged subjects (9-11).

A number of studies have demonstrated a beneficial action of angiotensin converting enzyme (ACE) inhibitors in the treatment of several cardiovascular diseases $(12,13)$. These drugs act by inhibiting the conversion of angiotensin I to angiotensin II, blocking 
the renin-angiotensin system (RAS). In addition, other vasoactive peptides can be also modified by ACE inhibitors, especially bradykinin, which is potentiated by ACE blockage $(12,13)$. These effects elicit a decrease in arterial pressure in several experimental models of hypertension and clinical forms of human hypertension as well $(12,13)$. In addition, these drugs improve cardiac performance in patients with congestive heart failure, reducing cardiovascular risk and mortality $(12,13)$.

Studies performed on experimental models, particularly rats, have evaluated the effects of ACE inhibitors on aging. Concerning the cardiovascular system, these studies have demonstrated that ACE inhibitors reduce renal intravascular resistance (14) and thickness of the media and intima layers of large arteries (15). Moreover, ACE inhibitors improve the endothelial function of resistance vessels (16), and partially restore the impaired autoregulatory mechanism of cerebral blood flow due to aging (17).

Nevertheless, to our knowledge, the effect of ACE inhibitors on the alterations of ECG found in aging has not been previously examined in rats. Therefore, the aim of the present study was to evaluate ECG alterations in aged rats, as well as the effect of the ACE inhibitor captopril in this experimental model.

\section{Material and Methods}

Four-month-old male Wistar rats were divided into four groups. One group was treated with captopril dissolved in tap water $(0.5 \mathrm{mg} / \mathrm{ml})$ for 2 months $(\mathrm{N}=10)$, a second group was treated with captopril dissolved in tap water $(0.5 \mathrm{mg} / \mathrm{ml})$ for 20 months $(\mathrm{N}=7)$, a third age-matched time control group $(\mathrm{N}=10)$ drank only tap water for 2 months, and a fourth age-matched time control group $(\mathrm{N}=5)$ drank only tap water for 20 months. The rats drank about 20-30 ml/day of captopril solution which provided approximately
$30 \mathrm{mg} / \mathrm{kg}$ of captopril a day. The efficacy of this dosage of captopril has been demonstrated in a number of pharmacokinetic and pharmacodynamic studies in rats (18). All surgical procedures and protocols were in accordance with the Guidelines for Ethical Care of Experimental Animals and were approved by the Institutional Animal Care and Use Committee.

At the end of a 2- or 20-month period of treatment, the animals were submitted to acute ECG studies under tribromoethanol anesthesia $(250 \mathrm{mg} / \mathrm{kg}$, ip $)$. Electrodes were placed under the skin for recording the conventional bipolar limb leads (I, II, III), the unipolar limb leads (aVR, aVL and aVF), and the unipolar precordial (chest) leads (VA is immediately to the right of the sternum in the 4th intercostal space, VB is just to the left of the sternum in the 4th intercostal space, and $\mathrm{VC}$ is in the 5th intercostal space at the midaxillary line). In order to avoid errors in the position of the leads, the electrodes were always placed by the same person. The ECG was recorded using a three-channel digital ECG recorder (ER-65, Medikor, Budapest, Hungary) with a paper speed of $50 \mathrm{~mm} / \mathrm{s}$ and sensitivity of $0.5 \mathrm{mV} / \mathrm{cm}$. Each lead was recorded for $20 \mathrm{~s}$.

At the end of the acute ECG recordings, the animals were implanted with a pair of stainless-steel electrodes positioned inside the subcutaneous tissue for chronic recording of conventional bipolar limb lead II without the effect of anesthesia. The animals were also cannulated with polyethylene tubing placed into the femoral artery and vein for direct measurement of arterial pressure and drug administration, respectively. After the surgical procedures the animals were left to recover in individual cages for at least $24 \mathrm{~h}$.

On the following day, without the effect of anesthesia, the electrodes were connected to a bioelectric amplifier (model 8811A, Hewlett Packard, Waltham, MA, USA), and the ECG was continuously sampled (1000 
$\mathrm{Hz}$ ) with a personal computer (IBM/PC) equipped with a 12-bit analog to digital interface (CAD12/36 Lynx Tecnologia Eletrônica, São Paulo, SP, Brazil) for a period of $30 \mathrm{~min}$. At the end of the ECG recording, the arterial catheter was connected to a pressure transducer (model P23Gb Statham, Hato Rey, Puerto Rico) attached to a pressure amplifier (model 8805D, Hewlett Packard) which fed the arterial pressure signal to a personal computer. The efficacy of ACE blockade was evaluated by the attenuation of the hypertensive response elicited by angiotensin I $(100 \mathrm{ng} / \mathrm{kg})$ given through the femoral vein. Only rats showing an attenuation of at least $85 \%$ of the hypertensive response elicited by angiotensin I were considered to have the RAS blockade. After the test of ACE efficacy the rats were killed with excess anesthesia and had their hearts removed and weighed on a precision scale (Micronal B160, São Paulo, SP, Brazil).

The ECG tracings were analyzed visually always by the same person, who was not aware of the protocol. The following ECG parameters were examined: 1) RR interval, defined as the interval between the apex of adjacent $\mathrm{R}$ waves; 2) $\mathrm{P}$ wave duration; 3) PR interval, defined as the interval between the apex of the $\mathrm{P}$ wave and the $\mathrm{Q}$ wave (beginning of the QRS complex); 4) QRS duration; 5) QT interval (defined as the interval between $\mathrm{Q}$ wave and $\mathrm{T}$ wave apex), and 6) corrected QT interval [QTc, defined as the QT interval corrected for the heart rate by means of Bazett's equation: corrected QTc $=$ QT (in s)/RR (in s) ${ }^{1 / 2}$ ]. In small rodents, in contrast to humans, the $\mathrm{T}$ wave is not well characterized and appears as a shoulder of the QRS complex (Figure 1). Accordingly, in order to measure the QT interval we used the apex of the $\mathrm{T}$ wave which can be determined with high accuracy. ECG recordings were carried out for $20 \mathrm{~s}$ for each lead, and the ECG parameters described above were determined from each lead and averaged.

The 30-min ECG recordings were care- fully examined on the screen of the computer to identify premature heart beats. The total number of supraventricular (SVPB) and ventricular premature beats (VPB) were counted over the 30-min period. The classic definition of arrhythmias in humans, adapted to the high heart rate of the rat, has been described elsewhere $(19,20)$ and was used to define the severity of ventricular arrhythmias. Briefly: class 0 - no VPB, class 1 infrequent isolated unifocal VPB $(<30 / \mathrm{h})$, class 2 - frequent unifocal VPB ( $>30 / h)$, class 3 - multifocal ectopic beats, class 4 couplets of VPB, class 5 - triplets of VPB and non-sustained ventricular tachycardia ( $<6$ ectopic beats), and class 6 - ventricular tachycardia.

Data are reported as means \pm SEM. For ECG parameters and arterial pressure data, two-way ANOVA followed by Tukey's multiple comparison test was performed to evaluate the effects of treatment (captopril vs tap water) and age (young $v s$ aged). The arrhythmia data, i.e., incidence of premature beats, were analyzed by the Kruskal-Wallis

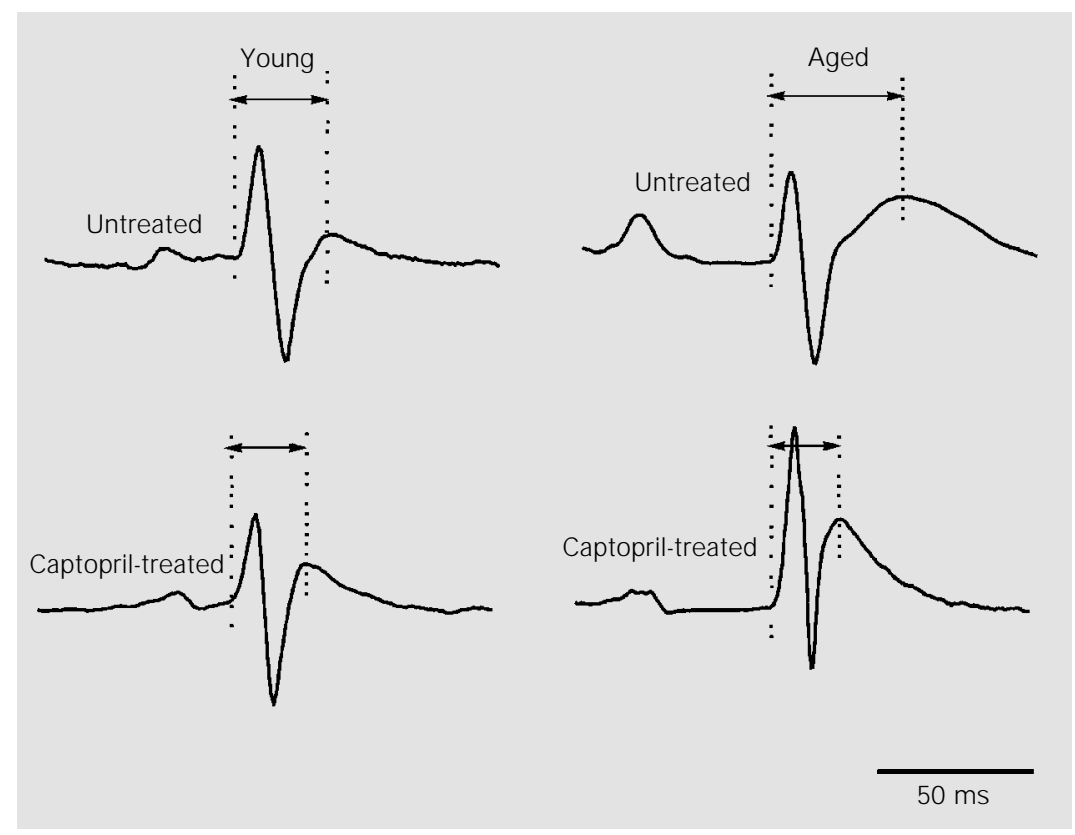

Figure 1. ECG tracings of representative rats of each experimental group. The arrows indicate the length of the QT interval. Notice the enlargement of the QT interval in untreated aged rats and the reduction of the QT interval in captopril treated aged rats. 
ANOVA test. The differences were considered significant when $\mathrm{P}<0.05$.

\section{Results}

Untreated aged rats were significantly heavier than untreated young rats $(512 \pm 22$ vs $460 \pm 15 \mathrm{~g}, \mathrm{P}<0.05)$. In contrast, young

Table 1. Baseline values (mean \pm SEM) of mean arterial pressure (MAP) and heart rate $(\mathrm{HR})$ in conscious male young and aged rats treated (Cap) or not (control, Con) with captopril.

\begin{tabular}{lrrrrr}
\hline & \multicolumn{2}{c}{ Young } & & \multicolumn{2}{c}{ Aged } \\
\cline { 2 - 3 } & Con $(\mathrm{N}=10)$ & Cap $(\mathrm{N}=10)$ & & Con $(\mathrm{N}=5)$ & Cap (N =7) \\
\hline MAP (mmHg) & $89 \pm 2$ & $93 \pm 4$ & & $97 \pm 2$ & $85 \pm 2^{*}$ \\
HR (bpm) & $381 \pm 11$ & $374 \pm 15$ & & $405 \pm 11$ & $311 \pm 25^{*}$
\end{tabular}

$* \mathrm{P}<0.05$ vs untreated aged rats (Tukey's multiple comparison test).

Table 2. Mean values ( \pm SEM) of ECG parameters measured in anesthetized young and aged rats treated (Cap) or not (control, Con) with captopril.

\begin{tabular}{lrrrrr}
\hline & \multicolumn{2}{c}{ Young } & & \multicolumn{2}{c}{ Aged } \\
\cline { 2 - 3 } \cline { 5 - 6 } & Con (N = 10) & Cap (N = 10) & & Con (N =5) & Cap (N =7) \\
\hline RR interval (ms) & $166 \pm 8$ & $172 \pm 5$ & & $152 \pm 6$ & $218 \pm 22^{*+}$ \\
P wave length (ms) & $23 \pm 2$ & $23 \pm 2$ & & $19 \pm 1$ & $18 \pm 2$ \\
PR interval (ms) & $50 \pm 3$ & $43 \pm 4$ & & $64 \pm 2^{+}$ & $63 \pm 3^{+}$ \\
QRS length (ms) & $22 \pm 1$ & $21 \pm 1$ & & $18 \pm 1$ & $16 \pm 2$ \\
QT interval (ms) & $26 \pm 3$ & $24 \pm 2$ & & $46 \pm 2^{+}$ & $33 \pm 4^{*}$ \\
Corrected QT (ms) & $64 \pm 6$ & $58 \pm 6$ & & $117 \pm 4^{+}$ & $71 \pm 6^{*}$ \\
\hline
\end{tabular}

$* \mathrm{P}<0.05$ vs untreated aged rats (Tukey's multiple comparison test).

$+\mathrm{P}<0.05$ vs young rats (Tukey's multiple comparison test).

Table 3. Number (mean \pm SEM) of supraventricular (SVPB) and ventricular premature beats (VPB) in conscious male young and aged rats treated (Cap) or not (control, Con) with captopril.

\begin{tabular}{lccrrr}
\hline & \multicolumn{2}{c}{ Young } & & \multicolumn{2}{c}{ Aged } \\
\cline { 2 - 3 } & Con $(\mathrm{N}=10)$ & Cap $(\mathrm{N}=10)$ & & Con $(\mathrm{N}=5)$ & Cap $(\mathrm{N}=7)$ \\
\hline SVPB & $0.5 \pm 0.1$ & $0.3 \pm 0.1$ & & $5.2 \pm 1.0^{+}$ & $3.0 \pm 0.5^{+}$ \\
VPB & $0.0 \pm 0.0$ & $0.0 \pm 0.0$ & & $8.4 \pm 3.0^{+}$ & $0.3 \pm 0.1^{*}$ \\
Total & $0.5 \pm 0.1$ & $0.3 \pm 0.1$ & & $13.6 \pm 3.3^{+}$ & $3.3 \pm 0.5^{*}$
\end{tabular}

$* \mathrm{P}<0.05$ vs untreated aged rats (Kruskal-Wallis ANOVA test).

$+P<0.05$ vs young rats (Kruskal-Wallis ANOVA test). rats (treated or not) and aged rats treated with captopril presented similar body weights $(434 \pm 26,460 \pm 24$ and $460 \pm 15 \mathrm{~g}$, respectively).

The basal mean arterial pressure and heart rate of conscious rats are shown in Table 1. Arterial pressure and heart rate were significantly lower in old rats treated with captopril compared to other groups.

The pressor response to angiotensin I was $35 \pm 3 \mathrm{mmHg}$ in young untreated rats and $4 \pm 2 \mathrm{mmHg}$ in young rats treated with captopril $(\mathrm{P}<0.001)$. Comparison of these values indicates a blockade of ACE by captopril of approximately $89 \%$. In aged rats, the pressor response to angiotensin I was 68 $\pm 18 \mathrm{mmHg}$ in untreated rats, and $1 \pm 2$ $\mathrm{mmHg}$ in rats treated with captopril $(\mathrm{P}<0.0001)$, indicating an ACE blockade of approximately $98 \%$.

The ECG parameters are presented in Table 2. The RR interval was similar in young (treated or not) and old untreated rats, but significantly larger in aged subjects treated with captopril. P wave length did not differ among groups. The PR interval was significantly larger in old than in young rats, but was not affected by captopril in either old or young rats. QRS length did not differ among groups. The QT and QTc intervals were significantly larger in old than in young rats, but were significantly reduced by captopril in old, but not in young rats (Table 2).

The incidence of SVPB was low in young rats, but high in old rats (Table 3). Captopril did not change the incidence of SVPB. VPB were absent in young rats (treated or not), but highly frequent in untreated old subjects (Table 3). Nevertheless, captopril significantly reduced VPB in old rats. Ventricular arrhythmias was 30 times less frequent than in untreated old rats (Table 3). According to the classification of ventricular arrhythmia adopted in the present study (20), all young rats belonged to class 0 , whereas $80 \%$ of the untreated old rats belonged to class 1, 2 or 3 . As a result of treatment with captopril, the 
percentage of old rats in class 1 was $29 \%$. No old rat treated with captopril was found in class 2 or 3, and no rat was found in classes 4,5 or 6 .

Relative heart weight $(\mathrm{mg} / \mathrm{g}$ of body weight) was found to be similar in young rats treated $(2.62 \pm 0.08 \mathrm{mg} / \mathrm{g})$ or not $(2.70 \pm 0.05$ $\mathrm{mg} / \mathrm{g}$ ) with captopril. Aged rats without any treatment presented an increase in relative heart weight $(3.44 \pm 0.14 \mathrm{mg} / \mathrm{g}, \mathrm{P}<0.05)$ as compared to young rats, but captopril brought the relative heart weight of aged rats (3.07 \pm $0.10 \mathrm{mg} / \mathrm{g}, \mathrm{P}<0.05$ ) within the range of young rats.

\section{Discussion}

The remarkable attenuation of the pressor response produced by angiotensin I demonstrated the efficacy of ACE blockade by captopril.

Heart rate did not change with aging, in agreement with previous reports in the literature (21-23). Berg (24) also found no heart rate changes in rats aged 219 days $(\sim 7$ months) or 557 days ( 18 months), whereas they detected bradycardia in older rats aged 851 days ( 28 months) and 951 days ( 31 months). In the present study, chronic (20 months) captopril treatment of aged rats reduced the basal heart rate compared to agematched control rats.

The bradycardia observed in aged rats treated with captopril may be associated with an increase in the vagal reflex controlling the heart rate caused by ACE inhibition (25), even though further studies are required to better understand this mechanism.

Concerning the other ECG parameters, the results of the present study have shown some differences in cardiac electrical activity with major alterations of PR and QT interval with aging. The PR interval is an index that correlates well with atrioventricular conduction, and an increase in this parameter indicates an impairment in atrioventricular conduction. The present finding that aging decreases electrical conduction in the atrioventricular node is in accordance with previous findings in experimental animals (24) and humans (26).

The QT interval, i.e., the time elapsed for ventricular repolarization (ventricular refractory period), was also increased in aged rats, corroborating ECG (24) and electrophysiological data (27) obtained for aged rats. A prolonged QT interval has been associated with cardiac arrhythmia and sudden death in humans $(1,2,5)$. At the cellular level, ventricular repolarization is prolonged in a number of cardiac disturbances such as myocardial hypertrophy, ischemia or congestive heart failure $(1,2,5)$. Changes of the QT interval have also been described in experimental models of hypertension (28). The other parameters examined in the present study were found to be unchanged by aging.

SVPB and VPB were the most frequent cardiac arrhythmias found in aged rats in the present study. Despite the short period of ECG monitoring (30 min), this finding substantiates previous literature reports describing a higher incidence of this kind of arrhythmia, linked to aging, in rats submitted to 24h Holter monitoring (20).

The impaired atrioventricular conduction (larger PR interval), the prolonged ventricular repolarization (larger QT interval), and the higher incidence of cardiac arrhythmias could be produced by degenerative lesions due to myocardial fibrosis and/or ischemia, as well as alterations in gene expression associated with the aging process $(7,8,29)$.

Treatment of rats with the ACE inhibitor, captopril, prevented the increase in the QT interval, but did not blunt the increase in the PR interval due to aging. Thollon et al. (30) have shown that electrophysiological changes induced by cardiac hypertrophy in infarcted rat hearts were considerably attenuated by ACE inhibitors. Gonzalez-Juanatey et al. (31) also reported a beneficial effect of ACE inhibitors on ECG alterations in humans. There is evidence that ACE inhibitors have a 
direct anti-trophic effect on cardiac myocyte proliferation, preventing myocardial fibrosis by means of the attenuation of the effect of angiotensin II, as well as inhibition of bradykinin degradation $(12,13)$. The development of apoptosis in heart tissue is also associated with the hyperactivity of local ACE (13). ACE inhibitors also improve the coronary blood flow $(12,13)$ which is impaired with aging $(7,8)$.

The prolonged PR interval observed in aged rats is probably related to the same structural and functional changes due to aging $(7,8)$. A possible explanation for the failure of captopril to normalize the PR interval is that ACE inhibition increases vagal control of the heart in aged rats (25), and it has been well documented that augmented vagal nerve activity increases the delay of atrioventricular conduction under physiological conditions (32). Therefore, the larger PR interval found in aged rats treated with captopril could be associated with a shift in the sympathovagal balance toward an increased parasympathetic activity. However, further studies are necessary to clarify this issue.

Chronic treatment with captopril almost eliminated the ventricular arrhythmias but did not affect SVPB in aged rats. This effect of ACE inhibitors seems not to be restricted to aging. In fact, a significant reduction in the incidence of ectopic beats has been observed in experimental $(33,34)$ and clinical (35) arterial hypertension, acute myocardial infarction (36) and congestive heart failure (37) after chronic ACE inhibition. There are a number of hypotheses to explain this antiarrhythmic effect. For instance, structural changes in fibrosis and/or cardiac hypertrophy and remodeling $(12,13)$, functional changes in coronary blood flow $(12,13)$, autonomic imbalance (25), ion channel dysfunction (20) and intracellular gene expression (38).

In the present study a cardiac hypertrophy evaluated by relative cardiac weight was reported in untreated aged rats. Cardiac hypertrophy in aged male rats is a common feature reported by many investigators $(7,8$, $28,38)$. The heart undergoes myocardial cell enlargement associated with myocardial fibrosis $(7,8)$. It is well accepted that this increase in heart weight is caused by the reduced diastolic stiffness of the left ventricle, and by changes in the properties of large arteries during the aging process $(7,8,28)$. At the cellular level, excitationcontraction coupling is prolonged by aging $(7,8,28)$.

Captopril was able to prevent cardiac hypertrophy in aged rats. This effect could be ascribed to the hemodynamic effects of captopril, which reduced the mean arterial pressure of aged rats. However, a direct effect of captopril inhibiting the trophic effect of angiotensin II on myocardial cells or fibrosis should be considered as well.

Rat aging is characterized by the development of ECG alterations associated with cardiac hypertrophy, typical of myocardial disorders. Chronic treatment with the ACE inhibitor, captopril, prevents some of these ECG alterations, as well as cardiac hypertrophy in rats. Therefore, ACE inhibitors have a remarkable beneficial effect on the heart during the aging process in rats.

\section{References}

1. Locati E \& Schwartz PJ (1987). Prognostic value of QT interval prolongation in post myocardial infarction patients. European Heart J oumal, 8 (Suppl A): 121-126.

2. Goldberg RJ, Bengtson J, Chen ZY, Anderson KM, Locati E \& Levy D (1991). Duration of the QT interval and total and cardiovascular mortality in healthy per- sons (The Framingham Heart Study experience). American J oumal of Cardiology, 67: 55-58.

3. Statters DJ, Malik M, Ward DE \& Camm AJ (1994). QT dispersion: problems of methodology and clinical significance. J ournal of Cardiovascular Electrophysiology, 5: 672-685.
4. Mayet J, Shahi M, McGrath K, Poulter NR, Sever PS, Foale RA \& Thom SA (1996). Left ventricular hypertrophy and QT dispersion in hypertension. Hypertension, 28: 791-796.

5. Peters RW, Byington RP, Barker A \& Yusuf S (1990). Prognostic value of prolonged ventricular repolarization following 
myocardial infarction: the BHAT experience. The BHAT Study Group. J ournal of Clinical Epidemiology, 43: 167-172.

6. Moreno FL, Villanueva T, Karagounis LA \& Anderson J L (1994). Reduction in QT interval dispersion by successful thrombolytic therapy in acute myocardial infarction. TEAM-2 Study Investigators. Circulation, 90: 94-100.

7. Folkow B \& Svanborg A (1993). Physiology of cardiovascular aging. Physiological Reviews, 73: 725-764.

8. Lakatta EG (1993). Cardiovascular regulatory mechanisms in advanced age. Physiological Reviews, 73: 413-467.

9. Reardon M \& Malik M (1996). QT interval change with age in an overtly healthy older population. Clinical Cardiology, 19: 949-952.

10. Perkiomaki JS, Sourander LB, Levomaki L, Raiha IJ , Puukka P \& Huikuri HV (2001). QT dispersion and mortality in the elderly. Annals of Noninvasive Electrocardiology, 6: 183-192.

11. Fleg J L (1988). Ventricular arrhythmias in the elderly: prevalence, mechanisms, and therapeutic implications. Geriatrics, 43: 23-29.

12. Unger T, Gohlke P \& Gruber MG (1990). Converting enzyme inhibitors. In: Ganten $D \&$ Mulrow PJ (Editors), Handbook of Experimental Pharmacology. Vol. 93. Springer-Verlag, Berlin, Germany, 377481.

13. Brown NJ \& Vaughan DE (1998). Angiotensin-converting enzyme inhibitors. Circulation, 97: 1411-1420.

14. Heudes D, Michel O, Chevalier J , Scalbert E, Ezan E, Bariety J, Zimmerman A \& Corman B (1994). Effect of chronic ANG Iconverting enzyme inhibition on aging processes. I. Kidney structure and function. American J ournal of Physiology, 266: R1038-R1051.

15. Michel J B, Heudes D, Michel O, Poitevin P, Philippe M, Scalbert E, Corman B \& Levy BI (1994). Effect of chronic ANG Iconverting enzyme inhibition on aging processes. II. Large arteries. American J ournal of Physiology, 267: R124-R135.

16. Atkinson J, Tatchum-Talom R \& Corman B (1994). Effect of chronic ANG I-converting enzyme inhibition on aging processes. III. Endothelial function of mesenteric arterial bed of rat. American J ournal of Physiology, 267: R136-R143.

17. Lartaud I, Makki T, Bray-Des-Boscs L, Niederhoffer N, Atkinson J , Corman B \&
Capdeville-Atkinson C (1994). Effect of chronic ANG I-converting enzyme inhibition on aging processes. IV. Cerebral blood flow. American J oumal of Physiology, 267: R687-R694.

18. Sun $Y \&$ Mendelsohn FA (1991). Angiotensin converting enzyme inhibition in heart, kidney, and serum studied ex vivo after administration of zofenopril, captopril, and lisinopril. J oumal of Cardiovascular Pharmacology, 18: 478-486.

19. Lown B \& Wolf M (1971). Approaches to sudden death from coronary heart disease. Circulation, 46: 130-139.

20. Carré $F$, Lessard $Y$, Coumel $P$, Ollivier $L$, Besse S, Lecarpentier $Y \&$ Swynghedauw B (1992). Spontaneous arrhythmias in various models of cardiac hypertrophy and senescence of rats: a Holter monitoring study. Cardiovascular Research, 26: 698705.

21. Tanabe S \& Bunag RD (1989). Age-related central and baroreceptor impairment in female Sprague-Dawley rats. American J ournal of Physiology, 256: H1399-H1406.

22. Wemer A, Rosa NR, Oliveira AR, Femandes TG, Belló AA \& Irigoyen MC (1995). Changes in blood pressure control in aged rats. Brazilian J ournal of Medical and Biological Research, 28: 603-607.

23. Irigoyen $M C$, Moreira $E D$, Wemer $A$, Ida $F$, Pires MD, Cestari IA \& Krieger EM (2000). Aging and baroreflex control of RSNA and heart rate in rats. American J ournal of Physiology, 279: R1865-R1871.

24. Berg BN (1955). The electrocardiogram in aging rats. J ournal of Gerontology, 10: 420-423.

25. Bunag R, Mellick J \& Allen B (1999). Abated cardiovascular responses to chronic oral lisinopril treatment in conscious elderly rats. American J ournal of Physiology, 276: R1408-R1415.

26. Fleg J L, Das DN, Wright J \& Lakatta EG (1990). Age-associated changes in the components of atrioventricular conduction in apparently healthy volunteers. J ournal of Gerontology, 45: M95-M 100.

27. Walker KE, Lakatta EG \& Houser SR (1993). Age associated changes in membrane currents in rat ventricular myocytes. Cardiovascular Research, 27: 1968-1977.

28. Baillard $C$, Mansier $P$, Ennezat $P V$, Mangin L, Medigue C, Swynghedauw B \& Chevalier B (2000). Converting enzyme inhibition nomalizes QT interval in spontaneously hypertensive rats. Hypertension, 36: 350-354.
29. Lakatta EG (1993). Myocardial adaptations in advanced age. Basic Research in Cardiology, 88 (Suppl 2): 125-133.

30. Thollon C, Kreher P, Charlon V \& Rossi A (1989). Hypertrophy induced alteration of action potential and effects of the inhibition of angiotensin converting enzyme by perindopril in infarcted rat hearts. Cardiovascular Research, 23: 224-230.

31. Gonzalez-J uanatey J R, Garcia-Acuna J M, Pose A, Varela A, Calvo C, CabezasCerrato J \& de la Pena MG (1998). Reduction of QT and QTc dispersion during longterm treatment of systemic hypertension with enalapril. American J ournal of Cardiology, 81: 170-174.

32. Thomas J r J X \& Randall WC (1983). Autonomic influences on atrioventricular conduction in conscious dogs. American J ournal of Physiology, 244: H102-H108.

33. Pahor M, Bernabei R, Sgadari A, Gambassi G, Lo Guidice PL, Pacifici L, Ramacci MT, Lagrasta C, Olivetti G \& Carbonin P (1991). Enalapril prevents cardiac fibrosis and arrhythmias in hypertensive rats. Hypertension, 18: 148-157.

34. Chevalier B, Heudes D, Heymes C, Basset A, Dakhli T, Bansard $Y$, J ouquey $S$, Hamon G, Bruneval P, Swynghedauw B \& Carré F (1995). Trandolapril decreases prevalence of ventricular ectopic activity in middle-aged SHR. Circulation, 92: 19471953.

35. Gonzalez-Fernandez RA, Rivera M, Rodriguez PJ , Fernandez-Martinez J, Soltero LH, Diaz LM \& Luggo JE (1993). Prevalence of ectopic ventricular activity after ventricular mass regression. American J ournal of Hypertension, 6: 308-313.

36. Singh SN, Karasik P, Hafley GE, Pieper KS, Lee KL, Wyse DG \& Buxton AE (2001). Electrophysiologic and clinical effects of angiotensin-converting enzyme inhibitors in patients with prior myocardial infarction, nonsustained ventricular tachycardia, and depressed left ventricular function. MUSTT Investigators. Multicenter Unsustained Tachycardia Trial. American J ournal of Cardiology, 87: 716-720.

37. Hattori Y, Atsushi S, Hiroaki F \& Toyama J (1997). Effects of cilazapril on ventricular arrhythmia in patients with congestive heart failure. Clinical Therapeutics, 19: 481-486.

38. Cooper IV G (1997). Basic determinants of myocardial hypertrophy: a review of molecular mechanisms. Annual Review of Medicine, 48: 13-23. 